\title{
Community-based participatory action research: transforming multidisciplinary practice in primary health care
}

\author{
Marcia Hills, ${ }^{1}$ Jennifer Mullett, ${ }^{2}$ and Simon Carroll ${ }^{2}$
}

Suggested citation

Hills M, Mullett J, Carroll S. Community-based participatory action research: transforming multidisciplinary practice in primary health care. Rev Panam Salud Publica. 2007;21(2/3):125-35.

ABSTRACT Objectives. Health care systems throughout the world are in the process of restructuring and reforming their health service delivery systems, reorienting themselves to a primary health care (PHC) model that uses multidisciplinary practice (MDP) teams to provide a range of coordinated, integrated services. This study explores the challenges of putting the MDP approach into practice in one community in a city in Canada.

Methods. The data we analyzed were derived from a community-based participatory action research (CBPAR) project, conducted in 2004, that was used to enhance collaborative MDP in a PHC center serving a residential and small-business community of 11000 within a medium-sized city of approximately 300000 people in Canada. CBPAR is a planned, systematic approach to issues relevant to the community of interest, requires community involvement, has a problem-solving focus, is directed at societal change, and makes a lasting contribution to the community. We drew from one aspect of this complex, multiyear project aimed at transforming the rhetoric advocating PHC reform into actual sustainable practices. The community studied was diverse with respect to age, socioeconomics, and lifestyle. Its interdisciplinary team serves approximately 3000 patients annually, 30\% of whom are 65 years or older. This PHC center's multidisciplinary, integrated approach to care makes it a member of a very distinct minority within the larger primary care system in Canada.

Results. Analysis of practice in PHC revealed entrenched and unconscious ideas of the limitations and boundaries of practice. In the rhetoric of PHC, MDP was lauded by many. In practice, however, collaborative, multidisciplinary team approaches to care were difficult to achieve. Conclusions. The successful implementation of an MDP approach to PHC requires moving away from physician-driven care. This can only be achieved once there is a change in the underlying structures, values, power relations, and roles defined by the health care system and the community at large, where physicians are traditionally ranked above other care providers. The CBPAR methodology allows community members and the health-related professionals who serve them to take ownership of the research and to critically reflect on iterative cycles of evaluation. This provides an opportunity for practitioners to implement relevant changes based on internally generated analyses.

Key words Health services research, primary health care, interprofessional relations, patient care team, health care reform, Canada.

1 School of Nursing, Centre for Community Health Promotion Research, Faculty of Human \& Social Development, University of Victoria. Send correspondence to: Marcia Hills, Centre for Community Health Promotion Research, University of Victo- ria, University House 3, Room 102, PO Box 3060, STN CSC, Victoria BC V8W 3R4, Canada; telephone: (250) 472-4102; fax: (250) 472-4836; e-mail: mhills@ uvic.ca.
2 Centre for Community Health Promotion Research, University of Victoria, Canada. 
Health care systems throughout the world are in the process of restructuring and reforming their health service delivery systems. Government reports and the academic literature consistently recommend that health care systems be reoriented to a primary health care (PHC) model, with multidisciplinary teams providing a range of coordinated, integrated services. Over the past 25 years, the multidisciplinary teamwork model has been recognized as a prerequisite for implementing PHC and for addressing the needs of clients (1); however, achieving multidisciplinary collaboration is another matter.

It is not easy for professionals, who have been educated and socialized by their disciplines, to shift their orientation to seamless multidisciplinary practice (MDP). They are more comfortable within their own disciplines, where they share a common theoretical understanding, similar approaches to problem-solving, and familiar terminology. It appears that it is difficult to implement collaborative team practice, even when it is valued. Establishing a team is more simple than creating collaborative teamwork (2). Likewise, sharing the same location and office space with various disciplines will not necessarily result in MDP.

Community-based participatory action research (CBPAR) is increasingly recognized among health professionals as a viable approach to collaboratively researching and improving community health (3-7). The underlying premise of the approach is that engaging community members and service providers as partners in the research process is not only respectful, it also increases the researchers' ability to identify, understand, and effectively address key issues. In a recent report on educating public health professionals for the 21st century, the Institute of Medicine (United States of America) included CBPAR as a focal area for supplementing traditional curricula (8).

Health professionals receive education and training in a wide range of disciplines, work in many types of settings, and are involved in numerous kinds of activities. Regardless of their backgrounds, health professionals need a framework that builds linkages and relationships among multiple health determinants and supports the achievement of the MDP approach.

The data analyzed in this study are derived from a CBPAR project that was used to enhance collaborative MDP in PHC. We draw from one aspect of this complex, multiyear project, aimed at putting $\mathrm{PHC}$ reform rhetoric into sustainable practice. All data come from work with one of the PHC settings. This PHC center sits in an urban community, within a mediumsized city of approximately 300000 people. The community itself, with a population of 11000 , is a residential and small-business community. The residential area is mixed, with many apartment units and a number of single-family dwellings. The neighborhood is diverse with respect to age, socioeconomic levels, and lifestyle. There is a sizable number of lowincome, single-parent families, and a high number of seniors (35\% over 65 years of age). Seventy-five percent of the dwellings are rentals.

The PHC center has an interdisciplinary team of physicians, nurse practitioners, clinicians, counselors/ educators, social workers, support staff, a management team, and a communitybased board of directors. It serves approximately 3000 patients annually, of which $30 \%$ are 65 years or older. The center has been running for over 30 years, making it one of the oldest community health centers in Canada. Its multidisciplinary, integrated approach to care makes it a member of a very distinct minority within the larger primary care system in Canada. In fact, one member of the research team often pointed out that Canada does not have a primary care system!

\section{Multidisciplinary practice: rhetoric or reality?}

One can draw three broad conclusions from the literature. The first is a general theoretical agreement that, in the context of an increasingly com- plex delivery system, patient/clientfocused care demands multidisciplinary, interprofessional teamwork in order to avoid service gaps and duplication and to achieve coordinated patient care (9-12). Secondly, most authors observe a paucity of empirical research on the relationship of effective multidisciplinary teamwork to improved patient care $(9,13-15)$. While some excellent attempts have been made to isolate factors that should improve care outcomes (14), overall, the area has not received sufficient attention. There is a need for more empirical research on specific interventions, describing in detail the improvements in care processes and outcomes. The third conclusion, a constant theme especially in relation to the PHC setting, is that multidisciplinary collaboration is a concept often recommended yet seldom practiced (16). Much of the literature emphasizes the recurrent failure of PHC teams to coalesce into effective MDPs.

Considering the paucity of research, there is a surprising level of consensus around the idea that effective collaborative teamwork in $\mathrm{PHC}$ is the best route to improving continuity, efficiency, and coordination of patient care. This consensus appears to be attributable to a more demanding and reflective patient population that is increasingly vocal about the lack of coordination and perceived inefficiencies in service delivery (17). It is this perceived need for better integrated PHC through a patient-centered, rather than professional-centered, delivery system that has led to the demand for more multidisciplinary teamwork. Nevertheless, there are other crucial factors behind the consensus observed.

Over the past 40 or more years, a conception of effective health services has developed that focuses on shifting resources from a "curative" delivery model to a "preventative" model of care. The context of this shift is often called the second epidemiological revolution, where mortality and morbidity in the industrialized world are caused by chronic diseases-diabetes, coronary heart disease, cancer, and severe mental health problems-rather 
than communicable ones. It is easy to demonstrate that chronic disease management demands a more preventative approach, with the main delivery system being PHC and access to a range of professions (the multidisciplinary team), as opposed to episodic health care, and its primary care physicians and acute care hospitals. The logic of the multidisciplinary PHC team stems from the need for a coordinated and efficient model of care delivery. Such a model allows a variety of practitioners to create an integrated package of care that is based on the individual patient's disease trajectories. The reason for a PHC team also comes from the need to monitor local determinants of health and advocate for positive changes that encourage healthy communities. Such a dynamic, proactive model of health care delivery demands effective multidisciplinary teamwork within a constantly developing collaborative framework.

But how do we achieve such a team approach to care? How can a collaborative multidisciplinary team approach be actualized? As stated above, the literature suggests that even practitioners who think they are practicing this way, in fact may not be. Creating opportunities for practitioners to reflect on their practice and to engage in critical dialogue with others may assist in developing insight about their practice. Many strategies, such as change management, continuous quality improvement, and continuing education, have been used to enhance MDP, with varying degrees of success (18). Another approach, CBPAR, engages practitioners in research about their practices. This research creates opportunities for them to generate their own "evidence," and to make decisions about how to change their practice based on this evidence.

\section{Community-based participatory action research: a catalyst for change}

The particular CBPAR approach used in this study was developed by two of the authors through a funding relation- ship with the British Columbia Health Research Foundation (6). They define CBPAR as a collaboration among community groups/practitioners, policymakers/decisionmakers, and researchers to create new knowledge or understanding about a practical issue in order to bring about change. CBPAR is a planned, systematic approach to issues relevant to the target community, requires community involvement in the research, has a problem-solving focus, is directed at societal change, and makes a lasting contribution to the community. The issues are identified by the people who have an interest or stake in it, and these stakeholders participate in all aspects of the research process. By engaging in iterative cycles of action and reflection, evidence for change is created and acted upon. CBPAR is an empowering philosophy of inquiry, not simply a method, framework, or strategy (19). CBPAR derives its philosophical principles from community development and applies the rigor of action science. CBPAR places stakeholders (government, community, practitioners, and researchers) in a unique position to facilitate the uptake of knowledge in order to initiate change in MDP.

It is critical to distinguish CBPAR from other forms of community research. A "community" may be a group that lives in the same geographic location or one that shares a common interest. Research situated in a community is not CBPAR per se simply because of its location. CBPAR must actively engage the stakeholders in all aspects of the research process. From the identification of the issue or question, to the analysis of data and writing of the project report, all stakeholders contribute their unique strengths and knowledge to enhance understanding of the phenomena under study. It is through this collaborative process that new knowledge is integrated with action to enhance $\operatorname{MDP}(20,21)$.

Israel et al. (3) describe almost a dozen advantages of using a CBPAR approach in health research: enhanced relevance, usefulness, and use of the research data by all partners; creation of a research team with the diverse range of skills needed to address complex problems; improved quality and validity of research; encouragement of critical subjectivity; promotion of the use of knowledge to benefit the community; strengthened research and program capacity; creation of more effective practices; bridging cultural gaps between partners; provision of funds and employment opportunities for community partners; directly and indirectly improving the health of the communities involved; and involving the marginalized. CBPAR provides the opportunity "for communities and science to work in tandem to ensure a more balanced set of political, social, economic, and cultural priorities that satisfy the demands of both scientific research and communities" (3). CBPAR is situated within a participatory paradigm and endorses a subjectiveobjective ontology that is both transactional and interactive (22). The focus of CBPAR is on investigating people's individual and collective perspectives and experiences, then using the knowledge gained to put meaningful change into practice.

In contrast to orthodox science, which presumes the knower and the known are separate and independent, CBPAR postulates that the knower participates in the known. Evidence is generated from four interdependent ways of knowing: experiential knowing, presentational knowing, propositional knowing, and practical knowing $(22,23)$. Experiential knowing refers to direct encounters with persons, places, or things. Presentational knowing is grounded in experiential knowing and is the way persons represent experiences through imagery, such as dance, art, drawing, writing, or stories. Propositional knowing is factual, empirical knowledge. This form of knowledge is most valued by orthodox science, but is seen as interdependent with the other three ways of knowing in CBPAR. Practical knowing is knowing how to do something. It is knowledge in action. This form of knowledge synthesizes conceptualizations and experiences into action.

The interdependent nature of the four ways of knowing is of critical in- 
terest in transforming MDP. Intentional action or change is practical knowing (knowledge in action), and practical knowing is grounded in propositional, presentational, and experiential knowing (23). Therefore, change can be considered to be based on evidence from all four ways of knowing (24).

A community-based research team cycles through iterations of reflection, action, and reflection. Theory (propositional knowing) about good MDP is built from MDP. As the group members test theory in the real world of their practice and reflect upon their experiences, propositional knowledge is created. The more congruent the four ways of knowing are, the more valid is the evidence for putting change into practice.

CBPAR does not view theory as something that is known and that "informs" practice. As Van Manen says, "Practice (or life) comes first, and theory comes later as a result of reflection" (25). CBPAR is based on the concept of praxis that is dialectical. It is a reflexive relationship, in which both action and reflection build on one another. In CBPAR, the cycling through the iterations of action and reflection creates praxis, and concomitantly generates evidence for future practice (6). This process grounds practice in theory, rather than applying theory to practice.

In this research project, a structured framework was used that consisted of a series of logical steps: identifying issues/questions to be researched, developing explicit strategies for service delivery (practice), putting the strategies into practice, recording what happens, reflecting on the experience, and making sense of the whole venture (26). In this way, evidence about what constitutes "best practice" in MDP was generated by practitioners, clients, and the community as they reflected on the various key elements of PHC (24).

\section{METHODS}

In the initial phase of the research project, PHC practitioners and com- munity members who had received health services were asked about their perceptions of the key elements of PHC. The idea was to develop a framework of multidisciplinary, integrated care from the realities of PHC practice. Two methods were used to collect this data: a modified critical incident technique and a Freirian strategy for a community forum $(24,27)$. The data were collected and analyzed in 2004 .

\section{Critical incident technique}

A modified critical incident technique was used to collect data from practitioners at the PHC sites (28). Members of the multidisciplinary team, including care providers and support staff, were asked to volunteer to be individually interviewed. A total of 21 interviews were conducted. The interview process engaged participants in not simply the act of being interviewed but also in the process of reflection. According to Bentz and Shapiro (29), "Action research proposes to help the system by helping it gather the information it needs in order to change or to, at least, explore the need for change."

Care team members were asked to recall incidents when key elements were effectively implemented and ineffectively implemented. The interview protocol was developed by the inquiry team and was based on the key elements identified in the PHC practice literature. The protocol is described in Figure 1. Interviews were recorded on audio tapes and transcribed.

After removing all identifying features, the transcribed interviews were distributed to all members of the inquiry team. A subgroup of volunteers consisting of practitioners, researchers, and decisionmakers conducted a thematic analysis (25). This method was particularly useful in identifying the specifics of a given concept and assisted the team in truly grasping the practice perspective of all the key elements of a PHC framework.

\section{Transcripts and field notes from community forums}

A community forum was held with members served by the PHC center. Posters in the PHC center and volunteers in other center activities invited community members to attend the forums. Thirty-two participants attended.

At the forum, the research project was described by members of the inquiry team. Participants engaged in a number of activities designed to ascertain their perceptions of PHC. A Freirian methodology (27) was used to elicit community members' perceptions of the philosophy and practice of $\mathrm{PHC}$ in the context of their local PHC center.

Transformative in nature, the Freirian methodology is designed to create critical reflection that results in new understandings, insights, and new actions. By utilizing a trigger, such as role play, participants are stimulated to reflect on the system from within the system. A trigger enables participants to discuss, reflect, and learn through facilitated questions and discussion. The method of forming a critical conscience follows three stages: investigation, thematization, and problematization (30). Praxis, therefore, is constituted by both a theoretical and an experiential component, and is mediated by dialogue.

Participants at the forum were recruited to partake in a role play simulating a waiting room in a PHC facility. Some participants were given cards that instructed them to play a multidisciplinary team member: physician, nurse, nurse practitioner, nutritionist, homeopath, naturopath, or social worker. These role-play participants sat behind the reception desk. Other participants were given a card asking them to play the role of a client with any one of a number of different ailments and/or concerns. They were instructed to approach the receptionist, simulating the typical interactions that occur on a visit to this PHC center. This role play activity was followed by a lively discussion. Critical dialogue was prompted by a series of questions de- 
FIGURE 1. Critical incident interview questions used in community-based participatory action research in a community in Canada, 2004

\section{General}

- Tell me briefly about the kind of work that you do.

- In a few words, how would you summarize the general aims and purposes of primary health care practice?

\section{Positive incident}

- Take a few minutes to think about a time in your practice when you felt that things went well. A time in your day to day work that seemed to be successful or productive in terms of the overall aims of primary health care. Tell me about the situation. Who was involved? Was it uniformly positive, or were there negative elements/aspects as well?

- Tell me what you, and others involved DID that made you feel that the experience was a success.

- Were there other factors that contributed to the success of this experience?

- In summary, was there anything that stands out for you as being essential to the success of "doing" primary health care?

\section{Negative incident}

- Now think of a time in your practice when things did not go very well. A time in your day to day work when you were either frustrated in trying to "do" primary health care, or when it just didn't work out well. Tell me about the situation.

- Tell me what you and others involved DID that made you think that the experience didn't work out well.

- Were there other factors that contributed to the lack of success?

- In summary, was there anything that stands out for you as being of primary importance that contributed to the difficulties in "doing" or implementing primary health care?

\section{Summary}

- In the academic, and professional literature, primary health care is characterized as, or spoken about as, health and social care that is patient-centred, integrated, accessible, participatory, and equitable. It depends on intersectoral involvement, and includes components that the community defines as essential-such as health promotion, selfcare, and disease prevention activities. It means that treating the patient also means addressing some of the broader social determinants of health.

- How does this "fit" with your experience?

signed to elicit the participants' perceptions of how effectively the key elements of multidisciplinary, integrated care in PHC had been implemented. The protocol used to encourage critical dialogue is described in Figure 2.

\section{Data analysis}

Van Manen's method of analysis was used to analyze the data collected from both the critical incident interviews and the community forums (25). There are no set guidelines for doing this type of analysis; it is a thoughtful, reflective grasping of what is meaningful that renders significance to an experience. As Van Manen suggests, thematic analysis refers then to "the process of recovering the theme or themes that are embodied or dramatized in the evolving meanings of the work" (25). He continues that this method of analysis is "more accurately a process of insightful invention, discovery, or disclosure ... Grasping and formulating a thematic understanding is not a rule-bound process, but a free act of 'seeing' meaning... Themes may be understood as the structures of experience" (25). The occurrence of similar or related ideas can be clustered to constitute themes.

It is important to distinguish thematic analysis from other techniques, such as content analysis, analytic coding, taxonomic, or other data organizing practices common to ethnography or grounded theory method. Generally, these forms of content analysis posit their criteria before- hand, whereas thematic analysis tries to ward off any tendencies toward presupposition (25). The themes emerge directly from the data, from people's experiences of PHC practice.

\section{RESULTS AND DISCUSSION}

\section{Critical incident interviews}

Five themes regarding the essential ingredients of PHC emerged from the critical incident analysis: supportive/ flexible structures, roles, and resources; collaborative team/collaborative practice; sense of belonging/ownership; client-focused/integrated care; and equity/power. Of interest in these results are the strong agreement in two of the themes (of supportive/flexible 
FIGURE 2. Protocol for Freirian critical dialogue used in community-based participatory action research in a community in Canada, 2004

\section{Welcome and introductions}

The community members were welcomed, and members of the inquiry team provided some brief comments.

\section{Overview of the project}

Members of the inquiry provided background information about the project and answered preliminary questions that the community members had about the research.

Example: In Canada, most people access health services by going to a doctor at his/her office. At your primary health care centre, health services are set up differently. For example, you have access to several different health professionals and several different programs, different than you find at a physician's office.

We are doing a research project to understand the important components of delivering services the way your health centre does, and we are also trying to understand what could make your health centre work better. How can we improve services for clients of this primary health care centre?

\section{Purpose of the community forum}

The main purpose of this community forum is to have the community (users of the service) be involved in designing the framework for health service delivery that will be used by the PHC centre. In other words, what are users of primary health care services perceptions of the essential elements of PHC. What makes PHC work?

\section{Methodology}

A Freirian approach, which simply means using a trigger to stimulate thinking, and following with a series of questions that provokes critical dialogue. This approach will be used to stimulate dialogue and debate.

\section{Dialogue}

We will begin with a "trigger." We have created a role play about PHC practice. We are going to imagine that we are in the waiting room of a primary health care centre. Participants are given "role cards" and asked to imagine themselves as that person in that situation. The participants are asked to have fun and to exaggerate their roles.

The role play lasts about 15 minutes and is followed by a set of questions, such as:

1. What do you see here? What is going on?

2. How is this scenario similar or different to your experience of accessing services at your primary health care centre?

This will lead to further dialogue by posing the following questions.

3. What were you looking for when you first came to this primary health care centre?

4. What is it about this primary health care centre that makes you come back?

5. If there were something about the way that services are offered or organized at this centre that you would change, what would it be?

6. What do you think this centre offers that other places that offer health services, such as walk in clinics, or physician's private practice, don't?

These questions are used to guide the dialogue, rather than asked in a series to simply elicit answers or information.

structures, roles, and resources and of sense of belonging/ownership) and the high variability in the other three themes (of collaborative team practice, of integrated care, and of power relations).

There was consensus from the practitioners and community members that supportive/flexible structures and a sense of belonging were essential, and present in this PHC setting. For example, it was acknowledged that integration of care was strengthened when the multiple disciplines recognized and valued each other's strengths and contributions. It was agreed that effective practice was supported when professionals were aware of their complementary, overlapping roles, and were able to move beyond territorial issues. Client-centered care enabled the team to be flexible and create an environment where the right care provider would provide the right 
care. For example, one nurse said: "I think we are able here to be less hung up or focused on trying to define individual roles, and our goal is to simply make sure that whatever the particular issue is... and we're talking about basic individual care... whatever the issue is, the person who deals with it is the right person."

However, further analysis revealed that although the collaborative team approach was valued by all, there was much greater variability in how multidisciplinary work was actually practiced. In other words, there was a discrepancy between the ideal way to practice and the real-life examples. In practice, there was no shared vision of PHC and much ambiguity around how the multidisciplinary team functioned. Additionally, the impact of practice on the delivery of services and the impact of power on MDP did not reflect stated values. We realized that these tensions had to be critically examined in order to get MDP in line with the values held by the practitioners.

The inquiry team decided to look more closely at the areas of variability. We conducted a second in-depth thematic analysis using Van Manen's approach, paying particular attention to these three themes and their interrelationship. Four subthemes emerged from this analysis. First, team members frequently judged their contribution to the team and to client care in relation to the physician's practice. Second, physicians seemed to feel an ultimate responsibility for client care. Third, the concept of "health" (disease vs. broad determinants) influenced individual practice, as well as how highly another team member's practice is valued. Fourth, there was ambiguity in the definition of roles and the interplay among disciplines.

Subtheme 1: team members frequently judged their contribution to the team and to client care in relation to physician practice. Team members often described what they do as being supportive of the physician's work rather than of client's needs. For example, one nurse stated: "She's a difficult person to care for. Certainly she can be supported with many of the things that he [the physician] will find difficult, by our counselor, who's now seeing her." In this example, the contribution of the counselor's work rests in the ability to address issues that the physician would find "difficult" and not in the intrinsic value of the counselor's work vis-à-vis the client's needs.

Similarly, when nonphysician team members spent time talking with clients about the effectiveness of their medication, or carrying out health education, these activities were valued for saving the physician's time, rather than providing comprehensive care for the client. The following statement illustrates this: "And [in] the next visit to the doc, all that explanation [health education] has been done, and the doc just needs to review the symptoms and determine for him/herself that antidepressants would be helpful, and then write the script. So that saves a lot from their end too, I think." Another interviewee described a client who tested the physician's patience by chronically missing appointments and arriving late. Notice that the following anecdote from the interviewee/ counselor stresses her ability to placate the physician, rather than the importance of her counseling role: "She's [the client] a person who could very easily wear out the patience of a physician. Our youth outreach counselor has probably pursued her [the client] a little bit more, and been more flexible about appointments and so on."

Subtheme 2: physicians felt an ultimate responsibility for client care. Working as part of a multidisciplinary team means that practitioners share responsibility and accountability for the clients' care. In the interviews, however, it was evident that physicians felt the ultimate responsibility for the clients' care. Even when a dying patient received excellent care by others, as in the following example, the physician felt guilty for not being more involved: "Our nurse did all of that. She [the nurse] knew the situation better than I did and did the necessary home visits very frequently ... And then she [the client] died, and that was the ex- pected outcome, and everyone felt good about the situation. I felt a little bit uncomfortable with the whole process because I felt like my involvement with her [the client] over that time was less than it would've been previously, because we have this clinical nurse who has got good experience in that sort of thing. And she [the nurse] was not resistant to being involved as much as she was. So in the end it was just my own personal discomfort." Interestingly, the physician described the nurse as not "resistant to being as involved." He assumed the perception on the nurse's part that the physician would take responsibility for the care, and in this clinic that may be the case.

Contrast this situation to the following case where a physician advises a team member (a nurse) not to feel guilty and reassures the nurse that, in the end, the person is his patient and his responsibility: "And so I [the nurse] go back to the doc and said, 'Oh my, I missed that.' He [the doctor] said, 'Well, you assessed her [the patient's] back, and you knew something was wrong... You followed up, and did what you were supposed to do. Chuck the guilt here... In the end it's my patient.'" The reassurance amounts to telling the team member that she had done her part by passing the client on to the physician. The team member, on the other hand, feels guilty because she knows she did not explore the problem with the client.

Subtheme 3: concept of "health" influenced practice and perception. Many comments from team members and staff revealed that there is not yet a consensus on what constitutes health. Health was described differently, depending on whether the practitioner's discipline was aligned with traditional health services or with social services. A counselor, who worked in the part of the building where social services are usually offered, described the situation this way: "Well, I think the very first one is that everybody understands what primary health care is, that it doesn't mean just medical care...I think over on this 
side [this part of the building], because we spend more time working in the community, we tend to think of health in the broader sense. But also there are lots of times when we could spend more time communicating. So I think that's the most important piece, that everybody agrees what primary health care is, that it's not just medical."

One social worker described comprehensive care as integrated care, indicating that it is not enough to have the all the constituents of PHC in the same building, that is, social issues plus health issues. These services must be integrated. That social worker commented: "For me it was a goal that took some time, actually, to accomplish. But getting her [the client] to a place where she can get both her social services and her sort of more narrow health services in the same place, and those people [social services and health care professionals] have the potential at least to work together. I think they will have to work together because the physician, even in this setting, is not as understanding of some of the issues in her life as I would like to see him be."

For others, the promise of PHC is the expansion of the scope of medical care, which has yet to be realized at the health center. One nurse practitioner noted: "And so I think that that's essential, that we haven't talked about how we can spend more time and ... I know that we were excited about doing primary care, with the thought that it would expand the scope of medical care by bringing in nutritionists, or alternate health, or you know, getting into other kinds of things, and I'm feeling a bit frustrated that it hasn't really moved beyond the medical model significantly."

Some team members expressed frustration that other medical staff did not value the importance of the disciplines beyond their own and were not interested in meeting to discuss them. Additionally, some team members perceived that physicians did not understand that working as a team would not increase their workload, but would ultimately make their work easier. One nurse said: “Well, I would say that what stands out the most is that the medical staff, for whatever reasons, are focused inward and on their issues ... and don't even always come to staff meetings ... So we don't have a chance to talk about things. So I think that that's the biggest one, is having them recognize the significance of what we do, will actually make their work easier rather than them feeling like it adds to their work to do the other pieces."

Subtheme 4: ambiguity of roles and the interplay among disciplines. Part of the problem with implementing PHC multidisciplinary teams is the ambiguity of the roles. These are new concepts to many practitioners, and there are no role models for guidance. When there is a lack of clarity and a dearth of exemplars, they retreat to what is familiar. The following quote, from a nurse, illustrates how providers have experienced ambiguity, and the effect it has on practicing as a team: "I'm just not sure of how doctors and non-health service people work together. I don't have many good models of that. So I'm not much experienced with that. I also want to say that when people see the vision, they get energized and motivated, and vision means that you see the whole picture. So you don't get stuck in your little 'me' place, 'this is how I practice, and I don't want to give up how I practice.' I think what stops people from, or what keeps them holding on to the old stuff, is that they don't have enough security or detail in what that vision is going to be like, and that's because there aren't that many painted pictures out there."

Collaboration and sustained collaborative relationships require certain logistics. If all team members are not on site or there is no face-to-face communication, it is more difficult to share information and provide integrated care. Understanding the totality of the team member roles is often difficult without the practicalities of things, such as a room in which to meet. A nurse practitioner expressed this clearly: "We lost our social workers ... and all of a sudden, if I want to talk to this woman's social worker, who I used to talk to in the lunchroom or walk down the hall, and knock on her door, it was a telephone tag game. You play that telephone tag game for a few years until those social workers you knew are gone and you've lost track of them and you make phone calls and you don't get phone calls back. I think for collaboration to work well there needs to be some time for face-to-face collaborating, and those are hard moments to steal or create. The shared chart certainly helps, but a chart is very unidimensional, and there's certainly much more richness there that doesn't always get communicated."

In addition, the results indicated that only physicians thought that they were working in a multidisciplinary way. All other practitioners reported that they did not think that there was an effective team approach to client care.

\section{Community forum}

Several themes emerged from the analysis of the community forum transcripts. Some of the themes coincided with those that emerged from the critical incident interviews, while others told a different story. The two themes that mirrored the critical incident interviews were: (1) valuing the multidisciplinary team and (2) understanding health as more than medical care. Unlike the critical incident interviews with the practitioners, the community members did not comment on the ambiguity of the multidisciplinary roles, the physician being ultimately responsible for client care, or other providers being judged in relation to the physician. The themes that emerged, and some examples are described below.

Theme 1: valuing the multidisciplinary team. Several participants commented on the team approach and the difference it made to their care. In response to the role play that demonstrated people waiting to see the doctor, one participant said: "I would like to make another comment about the young family [in the role play] saying to the nurse practitioner, 'I want to see 
the doctor.' I had a young family who came to the practice and wanted to see the nurse practitioner-[they] got in quickly. It was for something like an eye, ear, nose, throat kind of thing that a nurse practitioner could make an assessment on very quickly. So, I think that knowing that and having knowledge about... what the nurse practitioner does really assisted with that process."

Another participant elaborated on this point and stated that by having a team approach "people coming in with a variety of problems aren't stone-walled, but are sent in the right direction, whereas sometimes the doctors just don't know what other agencies or services are out there."

In fact, participants also saw the team as very broad, extending beyond the practitioners or professionals. They included the receptionist, other members of the staff, and the volunteers, in their discussion. In this broader view, they did not see the conflict or tension between the team members identified by the practitioners in the critical incident interviews. As one participant explained: "[My parents] got all kinds of support from all of the staff here, not just the physicians and the nurse practitioner. In fact, I think it was the receptionist who connected my mom with the Alzheimer's support group. It made a huge, huge difference for her. My father passed away just about two years ago now, but she is still involved with that group that she started with, and so now she has become a support for other people."

Theme 2: understanding health as more than medical care. Not surprisingly, participant comments at the community forum focused more on a broader concept of individual health and the center's contribution to the community, and less on its medical aspects. Their comments reflected awareness that it is not the medical clinic that keeps one healthy, but the links between the multidisciplinary team members. One participant expressed it this way: "I realized that the project [the primary health care center] is not really just about a clinic-it is about caring for the community and what we can do for the people who live in the community to make their life better."

Participants articulated how the multidisciplinary team's broad approach to health created many opportunities for community members to engage in healthy living activities. For example, one participant stated: "Well, I think the project is more able than any other doctor's office or clinic could be to respond to the whole person. Because it isn't just a place where you come to see a doctor or a nurse practitioner or to see someone on the health side... If you have a child you can come here. If you want to create an organization that needs a place to meet, you can come here... If you have an idea that you think the community will benefit from, you can bring that idea here, and there is a good chance that that idea will grow ... And the team approach is very significantly different than from stand-alone services out in the community."

In addition, participants described how the broad concept of health, reflected in the team approach, impacted social determinants of health. In one such example, a description of preventing isolation for both young mothers and seniors, a young mother explained: "I started coming here to the drop-in baby group, and that helped me out. I got to make friends, a lot of my long-term friends have come from the project, and then I was able to go [to] the doctor here, so it was very helpful to me." Similarly, a senior stated: "When I first came I didn't really know what the project was all about. I didn't need medical advice or anything like that, but I met the volunteer coordinator. She had a project that we initiated, and it is still an ongoing project to keep the seniors living in apartments longer in order to create the health care in the hospices or wherever you go, along with therapy."

In attempting to determine how a center such as this might flourish in other jurisdictions, community members were clear that it is not these particular practitioners who are exceptionally caring or the neighborhood that is unique. Instead, the center's success comes from the supportive structures that allow team members to demonstrate their caring in different ways. For example, the role of volunteers is often that of catalyst for community development work. There is a large network with other community agencies that allows many services to remain universal, in that there is no charge for them. It is this relationship with the community that empowers the center to make a significant contribution and employ a broader approach to health. One participant stated, "Where this clinic is different from a regular doctor's clinic is there are things going on here that require people's participation-200 volunteers."

There was consensus at the forum that while the medical services may be the hook that draws most people to the center, the work of the volunteers and the community outreach changes the focus/value of the work from "doing for, to doing with." This is reinforced by opportunities to mingle with the practitioners on an informal basis. One volunteer said: "I went to a supper [at the center] with someone who did my Pap smear! ... You can also have this sort of informal relationship with them that I think is really special... The diversity of the staff and the volunteers offers a sense of community. Come for my health stuff, and, you know, be a part of the Board, like it makes me feel like I have a little hug in my life in the neighborhood."

All the study results were distributed and discussed at a care team meeting with participating practitioners and staff. This provided an opportunity for team members to debate issues and resolve discrepancies in implementing a multidisciplinary approach. Team members found the results surprising, but insightful, and made commitments to further explore their collaborative team practices.

In total, five reflection meetings were conducted with team members to provide further analysis, interpretation, explanation of results, and literature findings. In addition, information needs and next steps were discussed. A meeting outcome was the develop- 
ment of a framework for multidisciplinary team practice and integrated client care. The framework is currently being implemented and documented.

\section{CONCLUSIONS}

A growing number of health researchers and practitioners have suggested that the CBPAR approach to public health may add a useful, if not fundamental, aspect to the practice of PHC (3-7). Advocates of CBPAR believe that engaging community members in public health endeavors will ensure that social and cultural considerations of PHC issues will be more fully explored, and that interventions will be more responsive to community needs (3-5).

While there are obviously many approaches to implementing multidisciplinary teamwork in PHC settings, we found CBPAR methodology allows community members, and the healthrelated professionals who serve them, to take ownership of the research, and critically reflect on iterative cycles of evaluation. This provides an opportunity for practitioners to implement changes based on internally generated analyses that are not perceived as being dropped on them from "above." Our CBPAR approach helped us conduct the research project in ways that were respectful to the practitioners, and that enhanced the project design, implementation, and conclusions. By enabling the system to examine itself and explore the need for change, key barriers and underlying beliefs were revealed. The research design was based on questions that the practitioners found compelling and wanted to address. Also, the inclusion of practitioners in the interpretation of the findings led to more reflective conclusions and processes that also proved useful for program change.

Analysis of PHC practice revealed entrenched and previously unacknowledged ideas about its limitations and boundaries. In the rhetoric of PHC, MDP is lauded by many. In practice, however, this can be contradicted since collaborative, multidisciplinary team approaches to care are difficult to achieve. Our CBPAR approach revealed that in this PHC setting, team members frequently judged their contribution to the team and client care relative to physician practice, while physicians felt ultimately responsible for client care. The persistent concept of "health" as diseaseoriented, rather than incorporating broad determinants, influenced individual practice as well as how team members' practice was viewed and valued. In addition, although team members believed they were working collaboratively, ambiguity remained in how roles were defined and how disciplines should interact. The successful implementation of a MDP ap- proach to PHC requires a movement away from physician-driven care. This can only be accomplished after changing the underlying structures, values, power relations, and definition of roles within the health care system and the community at large, where physicians are traditionally regarded as being above other care providers.

The CBPAR approach provides practitioners with the opportunity to engage in critical dialogue and reflection with other team members; as a result, practitioners gain insights into their practice. When practitioners are engaged in research about their practice, they are presented with the opportunity to generate their own "evidence," and decide how best to change their practice to address the issues identified. Through the critical incident technique and the Freirian methodology, practitioners were able to reflect on their individual and team practice, and recognize the barriers to implementing collaborative practice. Processes to overcome barriers will be developed by the team.

This paper responds to the need for research that focuses on the shift from traditional to multidisciplinary care practices. Improved patient care is generally described as efficient, continuous, and coordinated. The benefits of a dynamic, proactive model of health care within MDP and a collaborative framework can be achieved using the methodological principles of CBPAR.

\section{REFERENCES}

1. Lowe F, O'Hara S. Multi-disciplinary team working in practice: managing the transition. J Interprof Care. 2000;14:269-79.

2. Platt LJ. Why bother with teams?: an overview. In: Casto MR, Julia MC, eds. Interprofessional care and collaborative practice. Pacific Grove: Brooks/Cole Publishing Company; 1994 . Pp. 3-10.

3. Israel $A B$, Schultz $A J$, Parker EA, Becker AB. Review of community-based research: assessing partnership approaches to improve public health. Annu Rev Public Health. 1998;19: 173-202.

4. Brownson RC, Baker EA, Kreuter MW. Prevention research partnerships in community settings: What are we learning? [editorial]. J Public Health Manag Pract. 2001;7(2):vii-ix.
5. Parker E, Margolis L, Henriquez-Roldan C. Assessing the capacity of health departments to engage in community-based participatory public health. Am J Public Health. 2003;93(3): 472-6.

6. Hills MD, Mullett J. Community-based research: collaborative action for health and social change. Victoria: University of Victoria Community Health Promotion Coalition; 2000.

7. Green LW. Health education's contributions to public health in the twentieth century: a glimpse through health promotion's rearview mirror. Annu Rev Public Health. 1999; 20:67-88.

8. Gebbie KM, Merrill J, Hwang I, Gupta M, Btoush R, Wagner M. Identifying individual competency in emerging areas of practice: an applied approach. Qual Health Res. 2002;12 (7):1000-10.

9. Leathard A. Inter-professional development in Britain: an overview. In: Leathard A, ed. Going inter-professional: working together for health and welfare. London: Routledge; 1994. Pp. 3-38.

10. Ovreteit J. Cooperation in primary health care. Uxbridge: Brunel Institute of Organisation and Social Studies; 1990.

11. Ovreteit J. Co-ordinating community care: organising multidisciplinary teams and care management in community health and social services. Buckingham: Open University Press; 1993.

12. West MA. Effective teamwork. Leicester: BPS Books; 1994 
13. McCallin A. Interdisciplinary practice-a matter of teamwork: an integrated literature review. J Clin Nurs. 1994;10:419-29.

14. Poulton BC, West MA. The determinants of effectiveness in primary health care teams. J Interprof Care. 1999;13(1):7-18.

15. Zwarenstein M, Reeves S. What's so great about collaboration? BMJ. 2000;320:1022-3.

16. Waskett C. Multidisciplinary teamwork in primary care: the role of the counsellor. Couns Psychol. 1996;9(3):243-61.

17. Gabe J, Kelleher D, Williams G, eds. Challenging medicine. London: Routledge; 1994.

18. Huntington J, Gillam S, Rosen R. Clinical governance in primary care: organisational development for clinical governance. BMJ. 2000;321 (7262):679-82

19. Allman D, Myers T, Cockerill R. Concepts, definitions, and models for community-based HIV prevention research in Canada. Toronto: University of Toronto; 1997.
20. Dressler WW. Commentary on community research: partnership in black communities. Am J Prev Med. 1993;9:32-4.

21. Hatch J, Moss N, Saran A, Presley-Cantrell L, Mallory C. Community research: partnership in black communities. Am J Prev Med. 1993;9 (suppl):27-31.

22. Heron J, Reason P. A participatory inquiry paradigm. Qualitative Inq. 1997;3(3):274-94.

23. Heron J. Co-operative inquiry: research into the human condition. London: Sage Publications; 1996.

24. Hills MD, Mullett J. Methodologies and methods for community-based research and evaluation. Victoria: University of Victoria Community Health Promotion Coalition; 2000.

25. Van Manen M. Researching lived experience: human science for an action sensitive pedagogy. Albany: State University of New York; 1990.
26. Reason P. Human inquiry in action: developments in new paradigm research. London: Sage; 1988.

27. Freire P. Pedagogy of the oppressed. London: Penguin Books; 1972.

28. Flanagan JC. The critical incident technique. Psychol Bull. 1954;51(4):327-58.

29. Bentz VM, Shapiro JJ. Mindful inquiry in social research. Thousand Oaks: Sage Publications; 1998.

30. Gadotti M. Reading Paulo Freire: his life and work (J. Milton, Trans.). Albany: State University of New York Press; 1994.

Manuscript received 22 September 2004. Revised version accepted for publication 14 February 2007.
RESUMEN

Investigación-acción participativa basada en la comunidad: transformación de la práctica multidisciplinaria en atención primaria de salud

\footnotetext{
Palabras clave
}

Objetivos. Los sistemas de salud de todo el mundo se encuentran en un proceso de reestructuración y reforma de sus sistemas de prestación de servicios, reorientándose hacia el modelo de atención primaria de salud (APS) que utiliza equipos de consultorios multidisciplinarios (CMD) para brindar un conjunto de servicios coordinados e integrados. En este estudio se exploran los retos de poner en práctica el enfoque de CMD en una comunidad urbana de Canadá.

Métodos. Los datos analizados se tomaron de un proyecto de investigación-acción participativa basada en la comunidad (IAPBC) llevado a cabo en 2004. Su objetivo era perfeccionar un CMD colaborativo en un centro de APS que atiende a una comunidad de 11000 personas, compuesta por una zona residencial y pequeños negocios, en una ciudad canadiense de aproximadamente 300000 personas. La IAPBC permite abordar de manera planificada y sistemática problemas importantes para la comunidad en cuestión, requiere la participación de la comunidad, se enfoca hacia la solución de los problemas, se dirige a lograr cambios en la sociedad y hace contribuciones duraderas a la comunidad. Se partió de un aspecto de este complejo proyecto de varios años, para transformar la defensa retórica de la reforma de la APS en una práctica real y sustentable. La comunidad estudiada era diversa en cuanto a la edad, las características socioeconómicas y los estilos de vida. Su equipo multidisciplinario atendía aproximadamente a 3000 pacientes al año, 30\% de los cuales tenían 65 años o más. Gracias a su enfoque multidisciplinario e integrado con respecto a la atención, este centro de APS pasó a formar parte de un selecto grupo dentro del extenso sistema de atención primaria de Canadá.

Resultados. El análisis del trabajo de APS puso de manifiesto ideas arraigadas e inconcientes acerca de los límites y las limitaciones de la atención prestada. En el sentido retórico de la APS, el CMD era elogiado por muchos. En la práctica, sin embargo, era difícil lograr el enfoque de equipo colaborativo multidisciplinario.

Conclusiones. La exitosa implementación de un enfoque de CMD en la APS exige apartarse del estilo de atención centrada en el médico. Esto sólo puede lograrse cuando cambian las estructuras subyacentes, los valores, las relaciones de poder y los papeles a desempeñar, definidos por los sistemas de salud y la comunidad en general, donde los médicos tienen tradicionalmente una posición por encima de la de otros proveedores de atención sanitaria. La metodología de IAPBC permite a los miembros de la comunidad y a los profesionales relacionados con la salud que los atienden apropiarse de la investigación y reflejarse críticamente en ciclos iterativos de evaluación. Esto ofrece a los médicos una oportunidad de implementar cambios importantes basados en análisis generados internamente.

Investigación sobre servicios de salud, atención primaria de salud, relaciones interprofesionales, grupo de atención al paciente, reforma en atención de la salud, Canadá. 